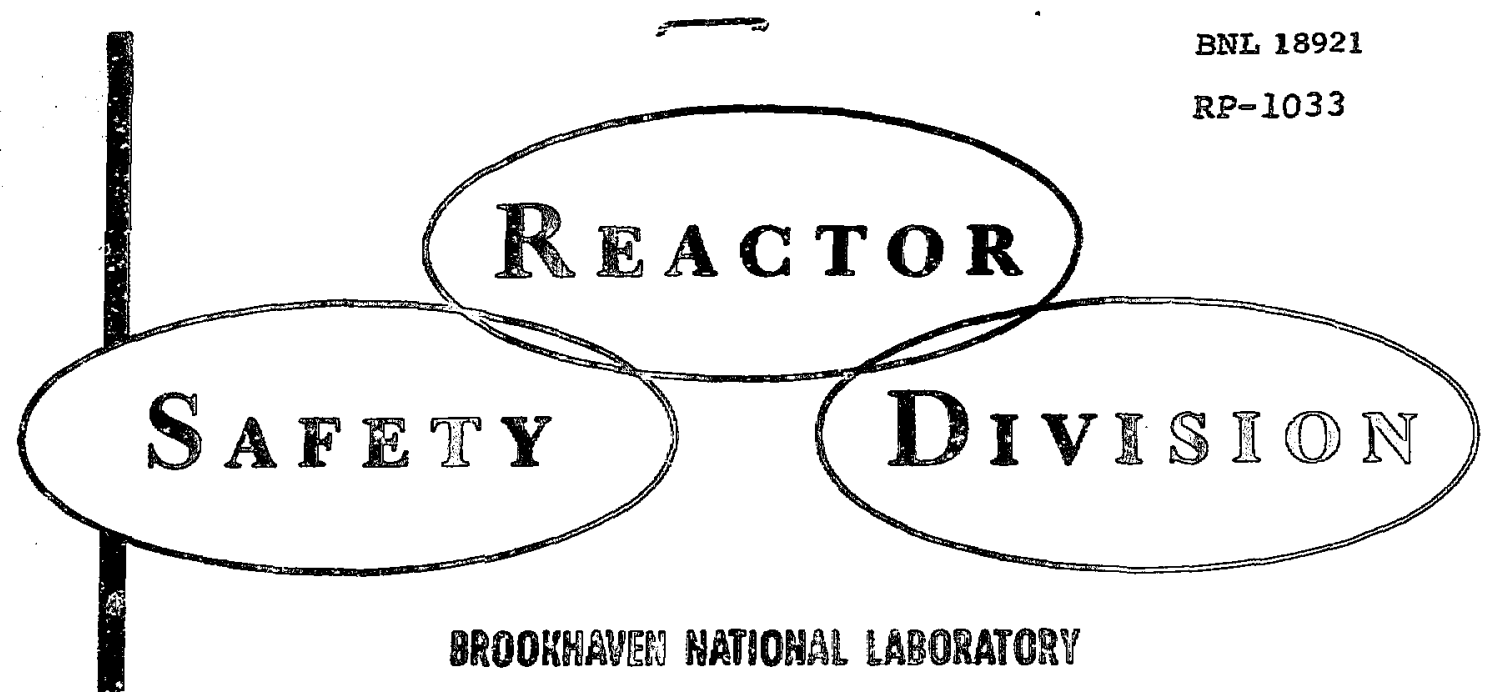

Axial Power Peaking Factors for

Point Beach 2

Gerald S. Lellouche

May 1974 
Axial Power Peaking Factors for Point Beach 2

\author{
G. S. Lellouche
}

Brookhaven National Laboratory

Upton, New York 11973

\title{
May 1974
}

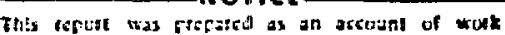

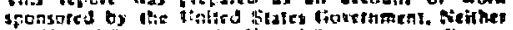

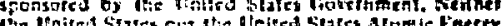
Ta e che or

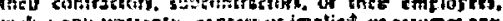

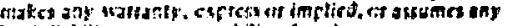

tepal liatitis os cerpuit:atiltis fol tho acrufary, com.

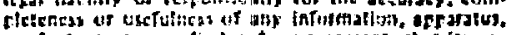

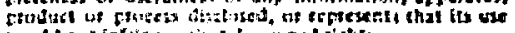

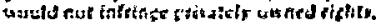




\section{Introduction}

This report diseusses a series of NoAH ealculations whose purpose is to check the accuracy of westinghouse predictions of some "load-following" transients. Generally, our calculations check the Westinghouse results quite elosely.

In order to meet the LOCA criteria, it is necessary for a monufacturer to demonstrate that the power peak to average does not exceed design values during normal operation. One type of normal operation is load-following during which a reactor will follow a prespecified power transient. For example, from an initial full power state it may reduce to a half power state for a specified number of hours, for example, $T(6)$, after which it is returned to a full power situation. Symbolically, this may be represented by $P(100$, $50,200)$. Control of the power level may be by the maneuvering D-Dank, whose rods may be inserted to different fractional depths at each power state. This is represented, for example. by $D(20,50,20)$ or by part-length rod bank which similarly may be represented by, for example, PLa $(60,0,0)$. Thus, a full load following transient may be represented by: $P(100,50,100), D(0,20,10), \operatorname{PLR}(62.5,0,0), T(6)$, which is read as: the reactor has been operating at $100 \%$ of full power with the D-Bank out and the part-length rods inserted $62.5 \%$ (that is centered, since they are $1 / 4$ length rods); the power 
is reduced to 50\% power, the D-Bank inserted to a depth of 20 percent and the PLR removed; this state lasts six hours at which time the power is raised to $100 \%$ of full power, the D-Bank witharawn to only a $10 \%$ insertion, while the PLR remains out. As far as we are concerned, the final state is assumed to continue indefinitely.

Our study has considered two aspects of the problem: first, do we concur with the solutions presented by westinghouse for particular load following transients, and second, do we agree with the structure of the fly speck graph.

\section{Comparison with westinghouse}

The festinghouse analysis is done using the code PANDA. The code uses a quasi-steady-state, twogroup majel containing a simplified power feedback model to account for Doppler effects fonly the fast absorption cross section is affected) and a more complex but still approximate (they use the outdated Bowring model and assume unit slip) voiding model: because the model assumes unit slip the void fractions will tend to be too large (Jence, too stabilizing). The time steps used are one hour in length. 
The Brookhaven analysis uses NEAH" which is an "equivalent one-group" model and contains more realistic feedback models for both fuel and coolant effects. The time step used was $1 / 3$ hour.

The solutions presented by Festinghouse are rontained in Attachment 3 (Proprietary) to the Point Beach 2 Fuel Densification Report. We feel that there is no good reason t:o repeat all of the BoL cases but have chosen one case with and one without part-length rod insertion. Fig. I shows a comparison with case 4 of the document cited above. The results are sufficiently close both in axial offset and power peak/average to make further discussion unnecessary. Similar conclusions can be drawn for a case with PLR $(\overline{6} 3,0,0)$ where Fig. 2. shows the axial power distribution at 8 hours into a transient and $\varepsilon$ ig. 3 shows the BNL prediction of the power peak/average for tise first 12 hours. These calculations (as well as others not reported) show (at least to our satisfaction) that for all the differences in the calculational techniques the predicted load-following transients are essentially the same as those obtained by Westinghouse. 
Some interesting phenomena occur when the PLR bank is used. Fig. 4 shows the effect at low power of a nearly centrally located PLR; as expected the maximum $F_{Z}$ is reduced by insertion of the PLR bank. At full power, however, different effects occur. Fig. 5 shows $F_{z}$ for three different cases, all at full power. The first has no xenon and no PLR and the curve is nearly sine shaped. Case 2 has the $P L R$ inserted, again witn no xenon effect, and the maximum $E_{Z}$ decreases as expected; but, as xenon builds into its equilibrium value, the maximum $F_{z}$ actually increases. The folklore that xenon buildup flattens the fower distribution is disproved by this result. The effect is caused by the decrease of boron concentration as xenon poisoning takes over. This increases the nagativity of the moderator coefficient and shifts the power peak sufficiently towards the inlet to accually increase the maximum $E_{Z}$. 


\section{Adequacy of the Ely speck Chart}

The LOCA accident analysis starts with the assumption of the maximum allowed power peak/average. This limiting value is set so as to preclude violation of the Final Acceptance Criteria (F.A.C.) ${ }^{\star}$ we address ourselves to a single question: is the envelope (the straight lines in the fly speck chart) located to include all reasonably probable cases.

To fully answer this question would require the reproduction of most of the cases done by westinghouse. We co not believe this is actually necessary and we substitute the indepenaent analysis of a number (not especially large) of BOL cases both with and without PLR insertion. The result of these calculations may be found in Fig. 6. The limit lines are those for Point Beach 2. The calculations comprise steadystate results with and without xenon, specific transients using various D-Bank insertion limits. PLR only before the shutdown to part power (i.e.. PLR $(x, 0,0)$ ). The only cases of interest are those on the line which crosses the Point Beach 2 limit line. This line of cases represents BoL steadystate without xenon or PLR and for the D-Bank partly inserted $10 \%$ to $60 \%$. Between $27 \%$ and $32 \%$ insertion we find results.

\footnotetext{
A number of other damage limits (and criteria for their avoidance) exist; it happens that the first of these occurs for the FAC.
} 
which exceed those allowed by Westinghouse. The maximum error (100(2.66-2.62)/2.62) is about $1.5 \%$ in peaking factor and quite likely is an indication of differing calculational methods. The error differences in Fig. 1 and Fig. 2 are generally about $\pm 1-2 \%$ in power paak/average.

In the newer $17 \times 17$ assembly cores the expected mode of operation during the early part of life will be to leave the PLR bank out of the core, and attempt to maintain the D-Bank at a fixed position (generally 10\% inserted). Juring a load following transient the D-Bank might be inserted to bring the core to part power, but then boron would be substituted as rapidly as is reasonable to allow replacement of the D-Bank at its original position. When returning to full power boron dilution would be used. The $3411 \mathrm{MW}, 12$ foot long core and the 3800/4100 MW, 164 inch long cores have less spatial stability and we were concerned that the non-interference procedure could lead to overshooting of the power peak/average. Indeed, this has not been found to be true and the transients' decay is essentially complete in 40-50 hours. The technical specifications state that the axial offset will be maintained between $-5 \%$ and $-15 \%$ (Fig. 16-3-10,11 RESAR 41 vol. viii) our analysis shows that this would be true for the $3411 \mathrm{MW}$ core at BOL but not for the $3800 / 4100$ series core. For the RESAR 41 core operating in the $3800 \mathrm{MW}$ configuration we find that the axial offset reaches $-17 \% 18$ hours into a transient described by $P(100,50,100), T(6), \operatorname{PLR}(0,0,0), D(10,10,10)$, and for the 4100 MW configuration we reach $-18 \%$ when 15 hours 
into the same transient. In both cases the initial axial offset is approximarely $-10.7 \%$.

The only way we know to bring the axial offset back within the target band would be to withdraw the D-Bank and reborate; however, it is not clear that the full withorawal of the D-Bank (it is only $10 \%$ inserted) is either allowed by the technical specifications or would in fact return the offset to its desired location. If no action at all is taken, the offset will return within eight hours.

\section{Conclusions}

We find that the Westinghouse calculations for Point Beach 2 are accurate within calculational error; that is, our methods compare with theirs withik $\pm 2 \%$ in peaking factor. This degree of accuracy is, however, sufficient to find cases which just cross the fly speck lines, thus indicating that the Iines are very closely drawn and leave little leeway. We find that the proposed operational scheme for load following for the $3800 / 4100$ RESAR-41 cores allows the fIux difference to exceed the technical specifications. 
A COMPARISON BETWEEN WESTINGHOUSE AND BNL IN PREDICTING THE LIMITING TRANSIENT REPERRED TO AS CASE 4, TABLE 2 UF ATPACHMENT 3 TO THE POINT BEACH DESIFICATION REPURT

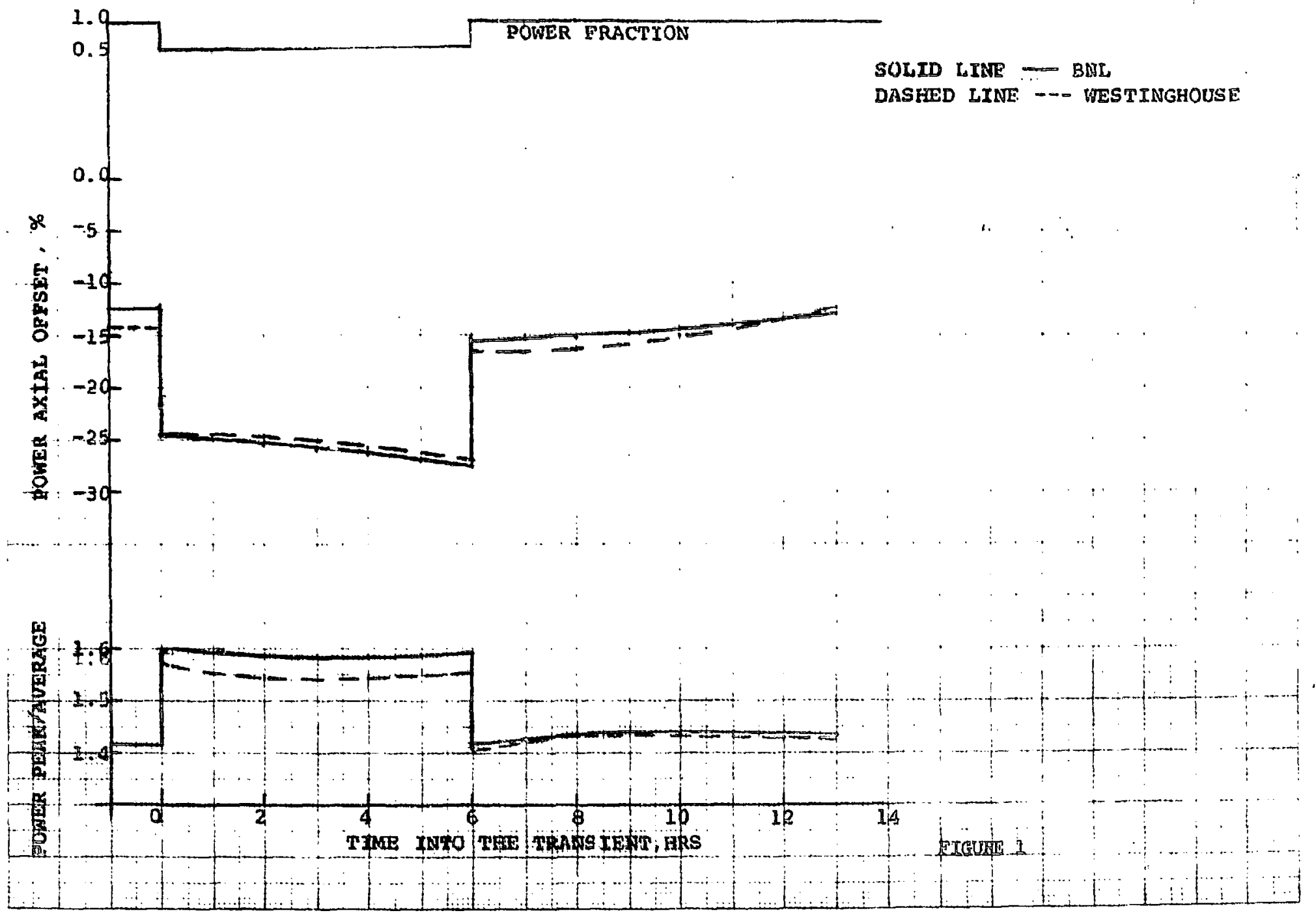


A COMPARISION OP POWER SHAPES 8 HOURS INTO A LOAD FOLLOWING TRANSIENT WYTH INITIALLLY (NEARLY) CENTRALLY LOCATED

PART LENGTE RODBANK

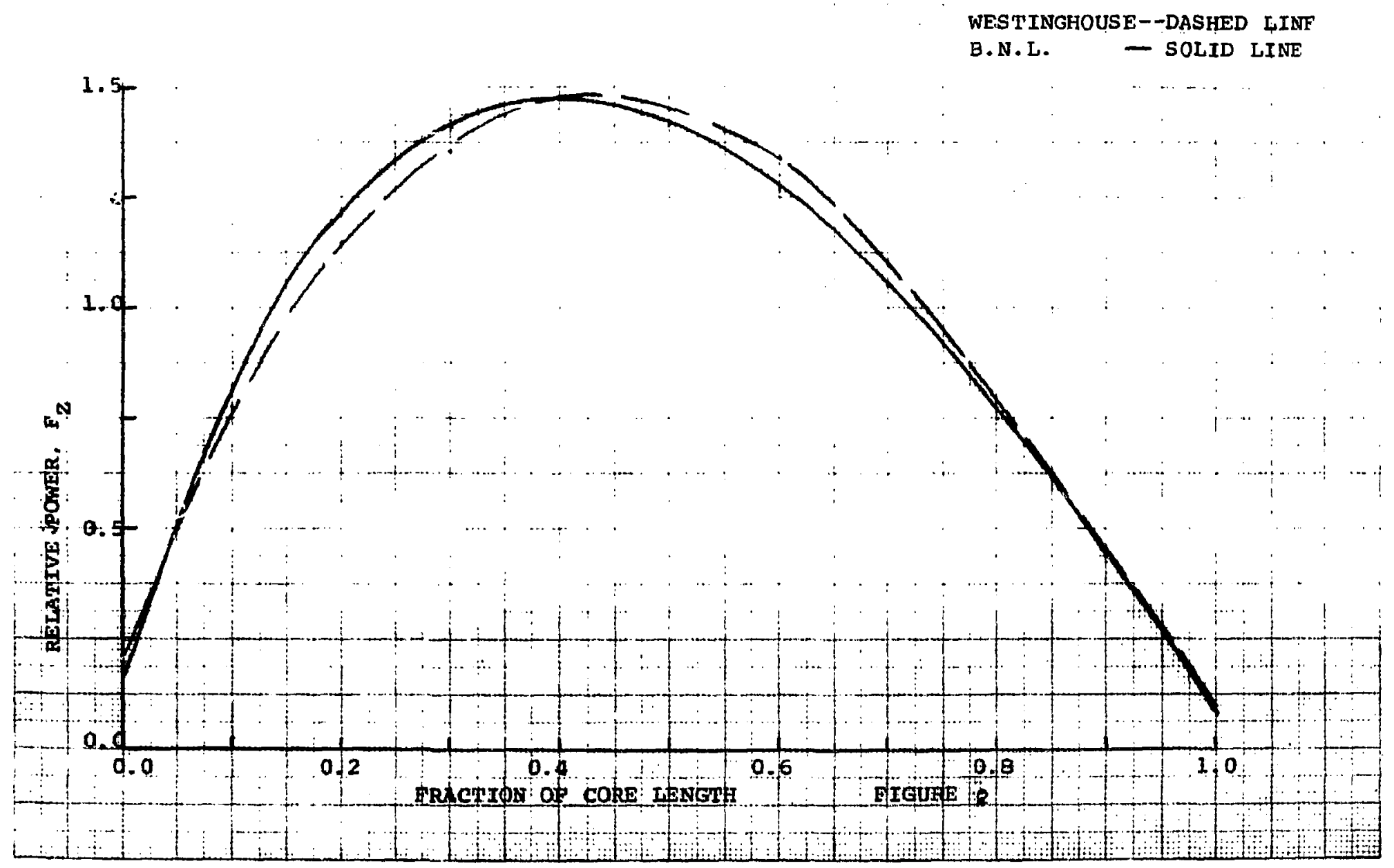




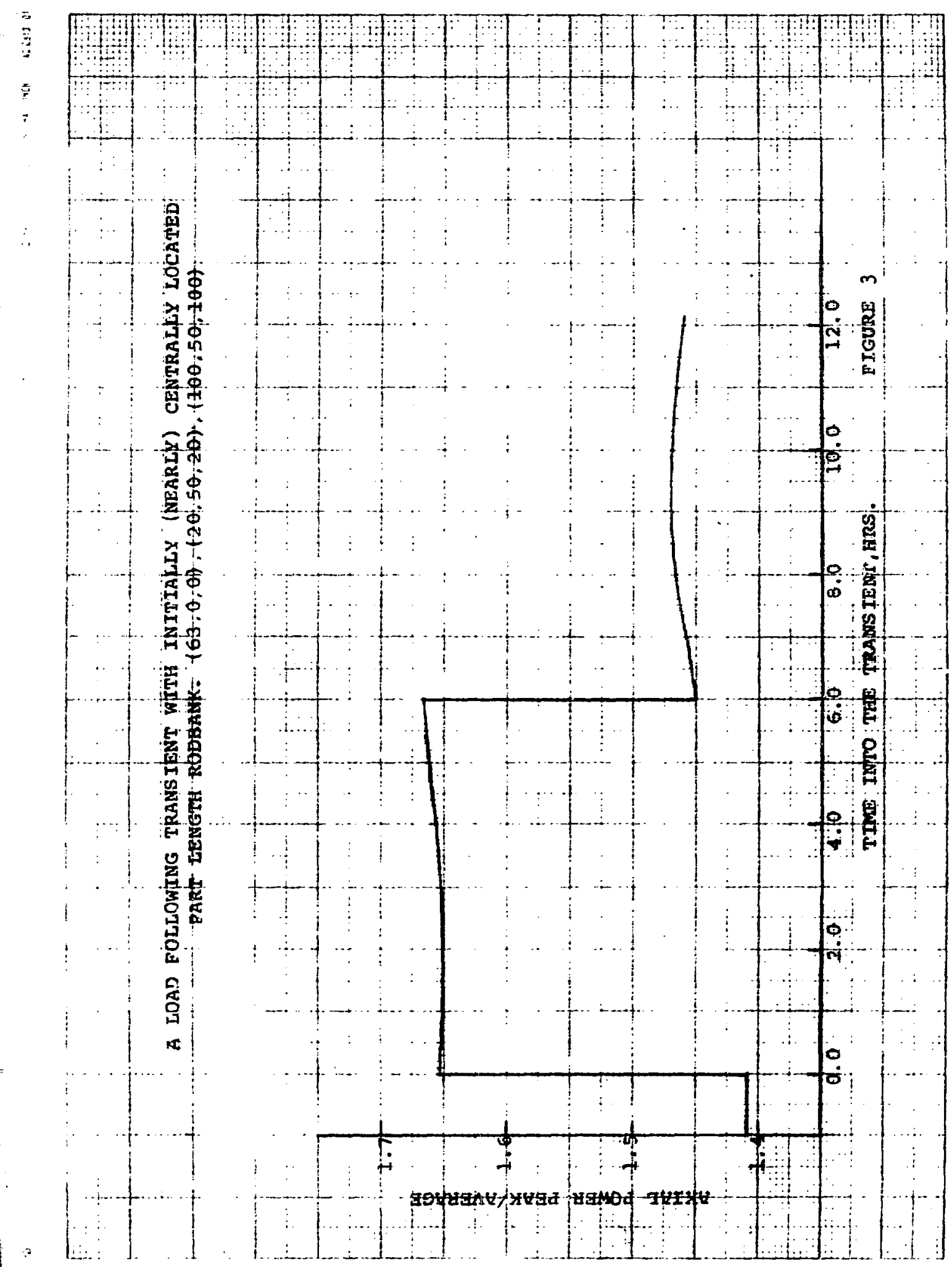


A COMPARISIOU OF THE LOW POWER AKIAL POWER DISTRIBUTION WITH AND WITHOUT (NEARLY) CENTRALLY LOCATED

PART - LENGTH RODBANK

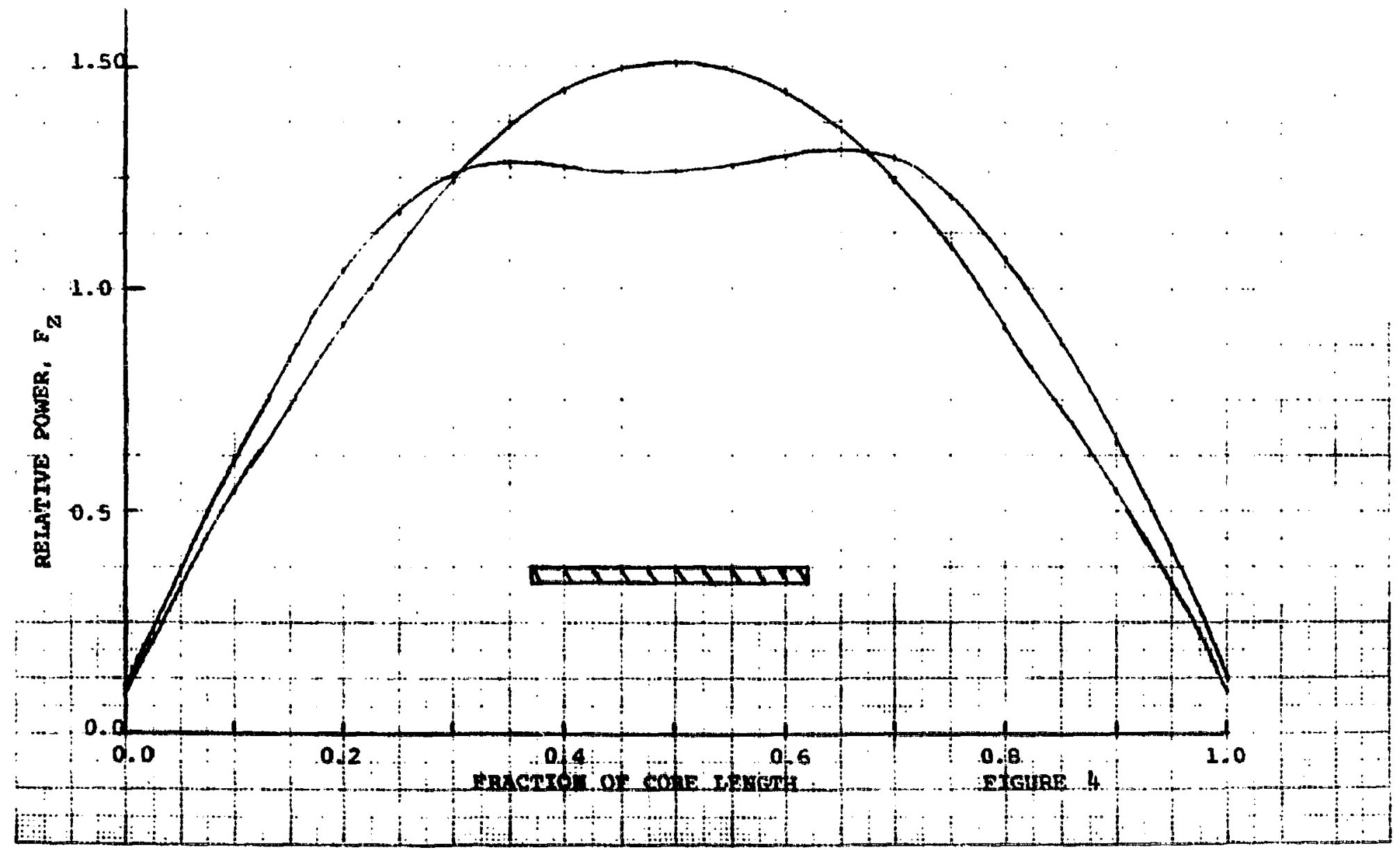




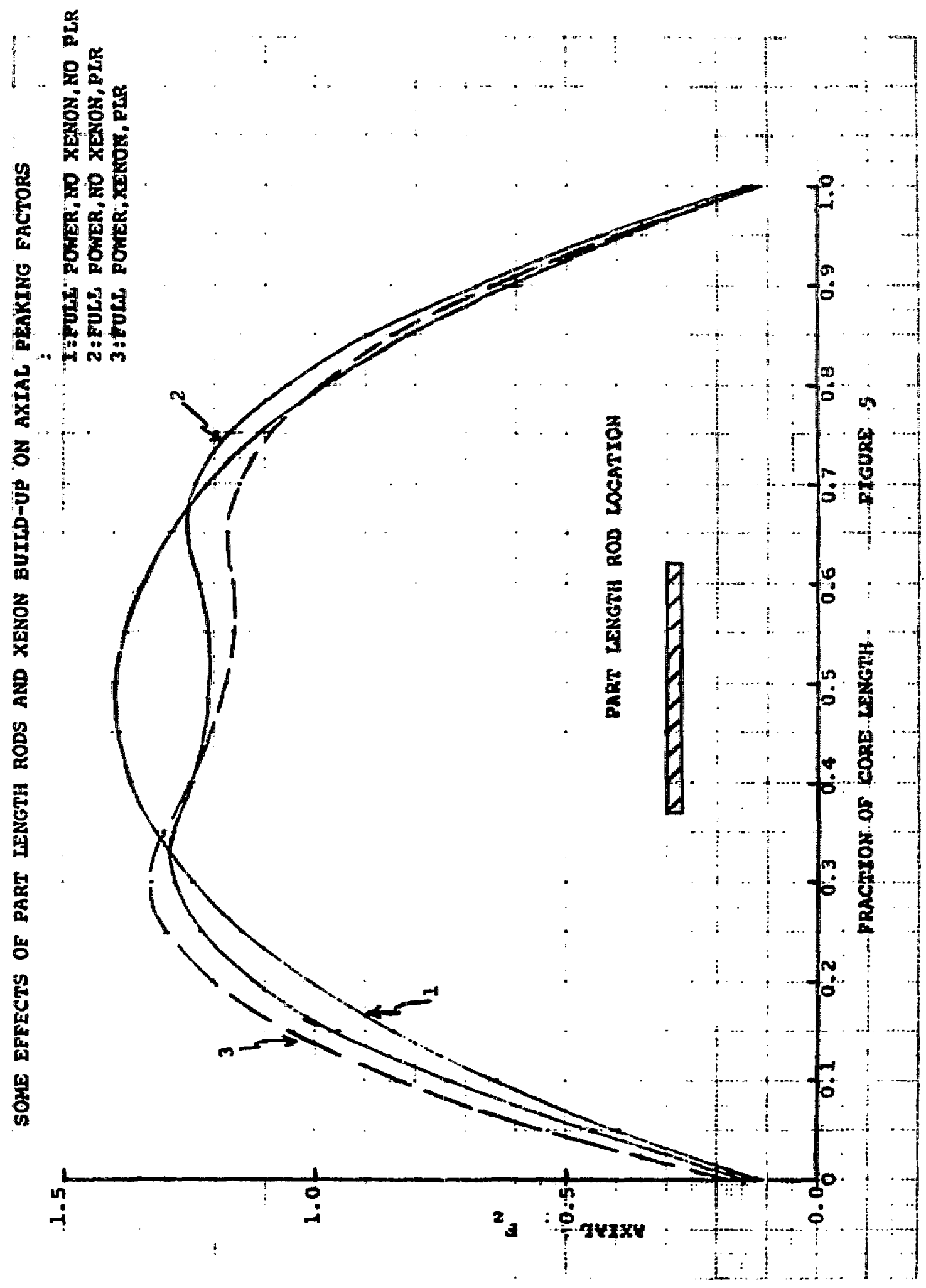




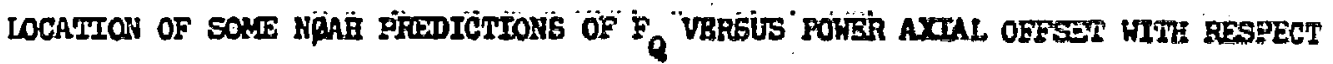
TO THE WRSTHGHOUSE FLYSPECK CBART LINLT LINES FOR FOINT BEACH 2

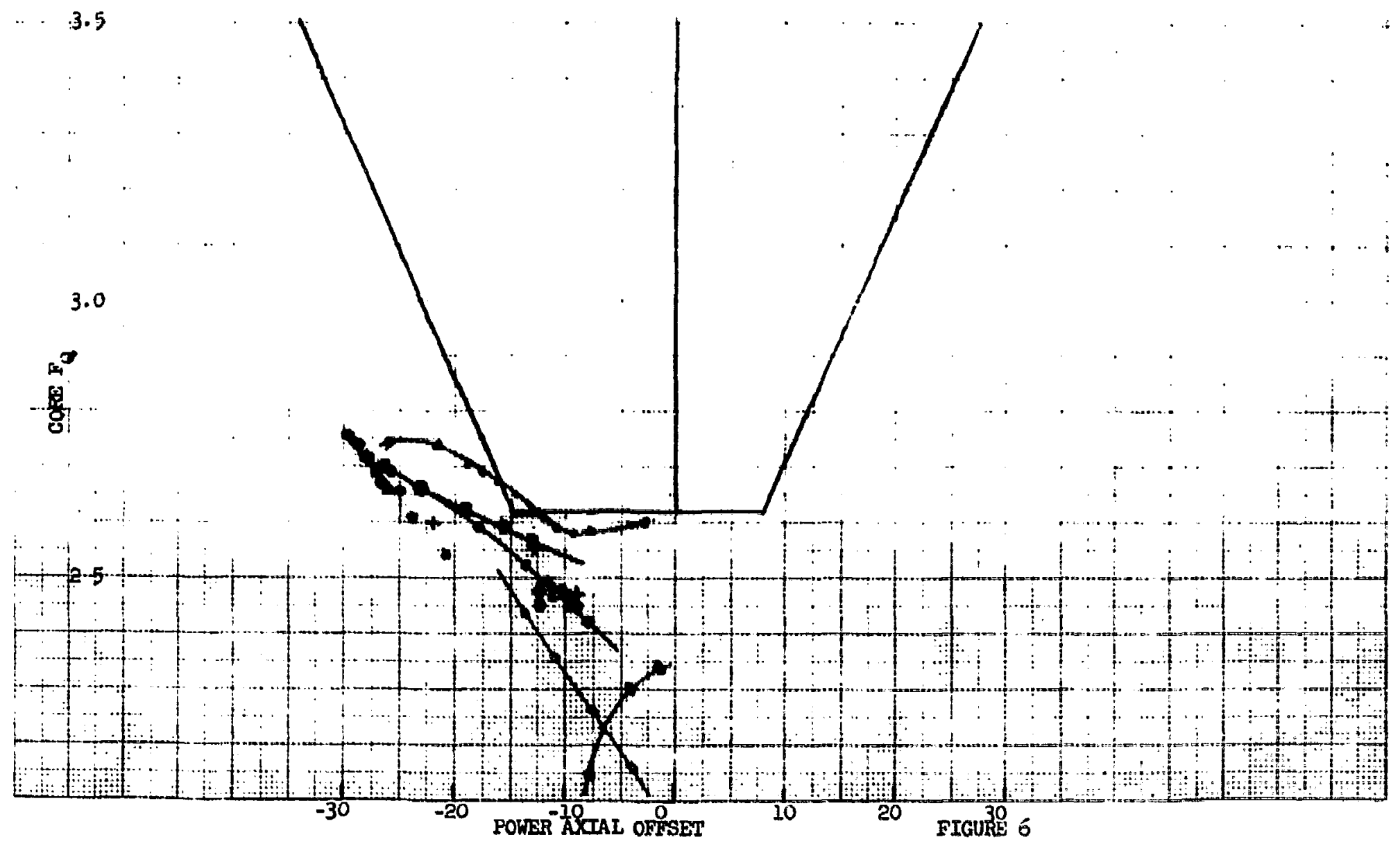

